\title{
Interpreting measurements of small strain elastic shear modulus under unsaturated conditions
}

\author{
Ahmed Hasan ${ }^{1}$ and Simon Wheeler ${ }^{1, \text { a }}$ \\ ${ }^{1}$ University of Glasgow, School of Engineering, Rankine Building, G12 8LT, Glasgow, UK
}

\begin{abstract}
Bender element testing of unsaturated isotropically compacted speswhite kaolin samples was used to investigate the variation of small strain elastic shear modulus $G$ under unsaturated conditions. Testing was performed in a suction-controlled triaxial cell and involved combinations of isotropic loading and unloading stages and wetting and drying stages. Analysis of the experimental results indicated that the variation of $G$ could be represented by a simple expression involving only mean Bishop's stress $p^{*}$ and specific volume $v$, with the only significant mismatches between measured and predicted values of $G$ occuring at the end of final unloading. No significant improvement of fit was achieved by incorporating additional dependency on degree of saturation $S_{r}$ or a bonding parameter $\zeta$. The proposed expression for $G$ reverts to a well-established form for saturated soils as $S_{r}$ tends to 1 .
\end{abstract}

\section{Introduction}

Bender element transducers [1] can be used to measure shear wave velocity $V_{s}$ and hence elastic shear modulus $G$ at very small strains (less than $0.001 \%$ ), where $G$ is related to $V_{s}$ and the bulk density $\rho$ of the soil by:

$$
G=\rho V_{s}^{2}
$$

Under saturated conditions and isotropic stress states, many authors, e.g. [2, 3, 4], have found that the value of small strain shear modulus $G$ for a particular soil is controlled by the mean effective stress $p$ and void ratio $e$. A commonly proposed form of expression for $G$ under these saturated conditions and isotropic stress states is:

$$
G=C f(e)\left(p^{\prime} / p_{a}\right)^{n}
$$

where $C$ and $n$ are soil parameters, $p_{a}$ is atmospheric pressure and $f(e)$ is a function of void ratio $[2,4,5]$.

Based on experimental evidence from tests on saturated sands, silts and clays at very small strains, many authors, e.g. [2, 6, 7], suggested a value of 0.5 for the exponent $n$ in Eq.(2). Various expressions have been proposed for the function $f(e)$ in Eq.(2), but the most common, as proposed by Shibuya et al. [6], is:

$$
f(e)=(1+e)^{-m}=v^{-m}
$$

where $v$ is specific volume and $m$ is a soil parameter. Oztoprak \& Bolton [4] suggested $m=3$.

For unsaturated soils, under isotropic stress states, based on experimental results from resonant column and bender element tests, Mancuso et al. [8] and Ng \& Yung [9] proposed expressions for small strain elastic shear modulus $G$ in terms of conventional unsaturated state variables of mean net stress $\bar{p}$ (where $\bar{p}=p-u_{a}$ ), matric suction $s$ (where $s=u_{a}-u_{w}$ ) and void ratio $e$. It was, however, unclear whether such expressions, which include no direct dependency on degree of saturation $S_{r}$, could properly capture variation of $G$ during wettingdrying cycles (where hysteresis in the water retention behaviour implies that $S_{r}$ is not uniquely related to suction $s$ ).

Authors such as $[10,11,12]$ interpreted measurements of small strain shear modulus $G$ in terms of alternative unsaturated state variables, such as mean Bishop's stress $p^{*}$, defined by Wheeler et al. [13] as:

$$
p^{*}=p-S_{r} u_{w}-\left(1-S_{r}\right) u_{a}=\bar{p}+S_{r} S
$$

For example, Chao [12] proposed that, under unsaturated conditions and isotropic stress states, $G$ could be related to specific volume $v$, mean Bishop's stress $p^{*}$ and a bonding parameter $\zeta$ introduced by Gallipoli et al. [14] (which depends upon both $S_{r}$ and $s$ ) by the following expression:

$$
G=C_{1} v^{-3}\left[\left(p^{*} / p_{a}\right)^{0.5}+C_{2} \zeta^{0.5}\right]
$$

where $C_{l}$ and $C_{2}$ are soil parameters.

It is unclear whether Eq.(5) is unnecessarily complicated, in including dependence on the bonding parameter $\zeta$. This bonding parameter represents the role of meniscus water bridges on mechanical behaviour [14], but Wheeler et al. [13] in the development of their large strain elasto-plastic constitutive model argued that these meniscus water bridges, while having a vital role in the yield behaviour of an unsaturated soil, would be relatively unimportant for elastic behaviour.

a Corresponding author: Simon.Wheeler@glasgow.ac.uk 
The aim in this paper was therefore to re-examine bender element measurements of $G$ from tests on three unsaturated compacted kaolin samples previously reported by Hasan \& Wheeler [15], to see if these could be successfully interpreted in terms of only $p^{*}$ and $v$. The tests included wetting-drying cycles as well as isotropic loading and unloading paths. A previous attempt [15] to interpret the same experimental measurements in terms of conventional unsaturated state variables $\bar{p}, s, v$ and $S_{r}$ had been rather unsatisfactory, because it had indicated dependency on all four variables and apparently contradictory results in terms of the influence of $S_{r}$ (in addition to the influence of $s$ ).

\section{Test programme}

\subsection{Sample preparation}

Three unsaturated samples of speswhite kaolin clay ( $L L=$ $68 \%, \mathrm{PL}=36 \%$ ) were prepared by compaction at a water content of $25 \% \quad(4 \%$ dry of the optimum from the standard Proctor compaction test). An isotropic form of static compaction was used [15]. The uncompacted soil mix was sealed within a large cylindrical rubber membrane and then subjected to an isotropic compaction stress of $390 \mathrm{kPa}$ in a triaxial cell. A smaller, $50 \mathrm{~mm}$ diameter, $100 \mathrm{~mm}$ height, triaxial test sample was then cored from the larger body of soil. Samples were subsequently tested in a suction-controlled triaxial cell fitted with bender elements.

\subsection{Bender element testing}

Two pairs of bender elements were used to measure shear wave velocity $V_{s}$. Both pairs transmitted horizontally across the sample, at the sample mid-height. One pair was aligned to give shear waves of vertical polarization and the other was aligned to give shear waves of horizontal polarization, providing measurements of shear wave velocities $V_{s h v}$ and $V_{s h}$ and hence elastic shear moduli, $G_{s h \nu}$ and $G_{s h h}$, respectively (where the second and third subscripts represent the transmission direction and polarization direction respectively).

Transmitter bender elements were excited by a single sinusoidal pulse, using a frequency of $20 \mathrm{kHz}$, corresponding to wavelengths of approximately $10 \mathrm{~mm}$. This frequency conformed to the recommendation of Leong et al. [16] that wavelengths should be less than $30 \%$ of the transmission path length and preliminary tests [17] indicated that it provided reliable and consistent values of shear wave velocity.

Values of wave velocity were calculated from the tipto-tip distance between transmitter and receiver bender elements and the measured travel time. Travel time was determined from transmitted and received signals, using a peak-to-first-peak method in the time domain. Preliminary tests [17] investigated four possible methods for determining travel time (using both time and frequency domains) and concluded that the selected method was the most reliable.

\subsection{Stress paths}

The stress paths followed in Tests A, B and C are plotted in terms of $\bar{p}$ and $s$ in Fig. 1. In all three tests the ascompacted suction was approximately $650 \mathrm{kPa}$ (point X in Fig. 1). After mounting in the triaxial cell, a mean net stress of $10 \mathrm{kPa}$ was applied (point $\mathrm{Y}$ in Fig. 1) and then samples were wetted to a suction of $300 \mathrm{kPa}$ (points $\mathrm{A}_{1}$, $B_{1}$ and $C_{1}$ in Fig. 1).

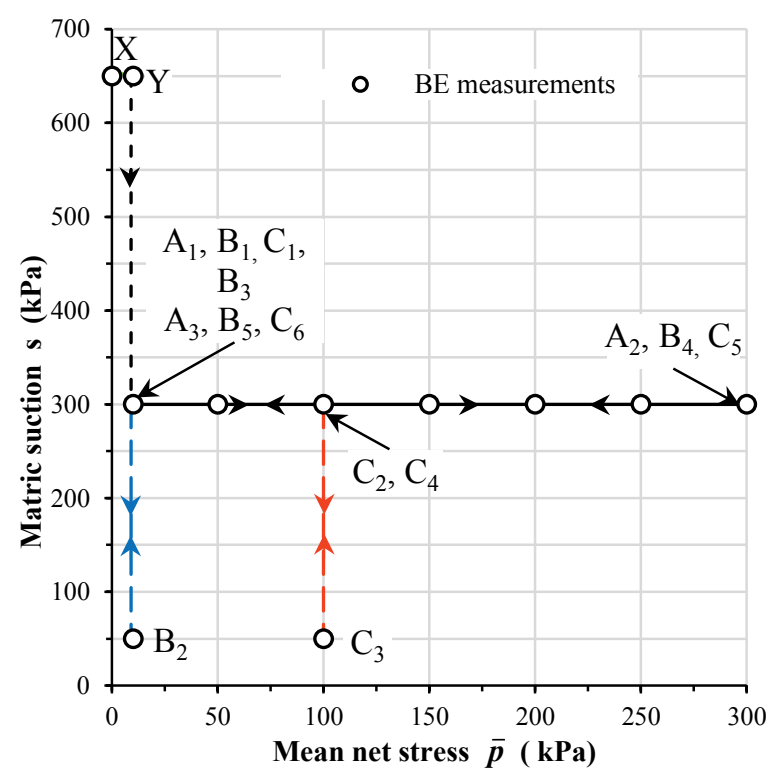

Figure 1. Stress paths for Tests A, B and C in $s: \bar{p}$ plane [15].

Test $\mathrm{A}$ involved isotropic loading $\left(\mathrm{A}_{1}-\mathrm{A}_{2}\right)$ at constant suction $(s=300 \mathrm{kPa})$ to $\bar{p}=300 \mathrm{kPa}$, followed by isotropic unloading $\left(\mathrm{A}_{2}-\mathrm{A}_{3}\right)$ to $\bar{p}=10 \mathrm{kPa}$. Test $\mathrm{B}$ involved a wetting-drying cycle $\left(\mathrm{B}_{1}-\mathrm{B}_{2}-\mathrm{B}_{3}\right.$ in Fig. 1$)$ at $\bar{p}=10 \mathrm{kPa}$ to a minimum $s$ of $50 \mathrm{kPa}$, followed by isotropic loadingunloading $\left(\mathrm{B}_{3}-\mathrm{B}_{4}-\mathrm{B}_{5}\right)$ at $s=300 \mathrm{kPa}$. Finally, Test $\mathrm{C}$ involved isotropic loading $\left(\mathrm{C}_{1}-\mathrm{C}_{2}\right)$ at $s=300 \mathrm{kPa}$ to $\bar{p}=100 \mathrm{kPa}$, followed by a wetting-drying cycle $\left(\mathrm{C}_{2}-\mathrm{C}_{3}-\right.$ $\mathrm{C}_{4}$ ) at $\bar{p}=100 \mathrm{kPa}$ to a minimum $s$ of $50 \mathrm{kPa}$ and then isotropic loading and unloading $\left(\mathrm{C}_{4}-\mathrm{C}_{5}-\mathrm{C}_{6}\right)$ at $s=300 \mathrm{kPa}$.

Loading and unloading stages were performed by increasing or decreasing $\bar{p}$ at a fixed rate of $2 \mathrm{kPa} /$ hour, whereas wetting and drying stages were performed by applying a rapid change of $s$ to the sample boundary and then waiting until inflow or outflow of water reached an appropriately low rate. Bender element (BE) tests were performed at intervals throughout each test (see Fig. 1).

The purpose of the wetting-drying cycles in Tests B and $\mathrm{C}$ was to ensure that during subsequent isotropic loading and unloading the values of $S_{r}$ were different for samples $\mathrm{A}, \mathrm{B}$ and $\mathrm{C}$ (due to hysteresis in the retention behaviour), even though the suction value was identical at $300 \mathrm{kPa}$ in all three cases. For sample $\mathrm{C}$ the wetting was expected to produce collapse compression, whereas collapse compression was not expected in the wetting performed in Test B, so that the subsequent loading stages of Tests $\mathrm{B}$ and $\mathrm{C}$ were expected to be at different values of $v$. 


\section{Test results}

\subsection{Variation of specific volume $v$}

Fig. 2 shows the variations of $v$ for all three tests. The two data points at the end of each isotropic loading stage represent the start and end of a 24 hour rest period. There were small differences in the measured initial values of $v$ for the three samples (after initial wetting to $s=300 \mathrm{kPa}$ ). Investigation over a large number of tests suggested that this was mainly attributable to small errors in measurements of initial sample volume rather than to variability between samples. Results were therefore adjusted so that initial values of $v$ were identical for all three samples (see $A_{1}, B_{1}$ and $C_{1}$ in Fig. 2).

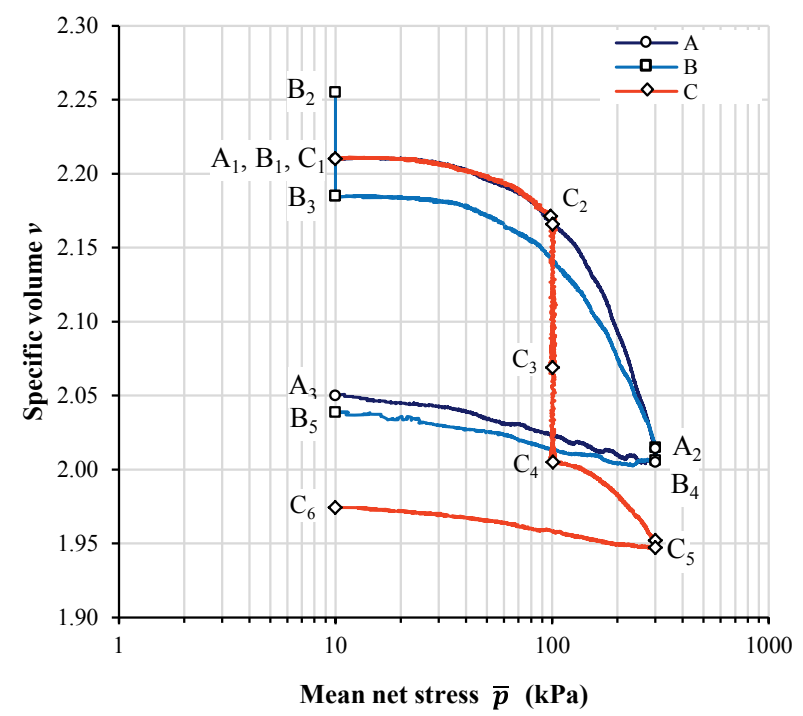

Figure 2. Variation of specific volume [15].

The variation of $v$ during Test A (see Fig. 2) showed, as expected, significant irreversible compression during the isotropic loading-unloading cycle $\left(A_{1}-A_{2}-A_{3}\right)$, with the suggestion of yielding during loading.

During Test $\mathrm{B}$, swelling was observed during the wetting stage $\left(B_{1}-B_{2}\right)$ (see Fig. 2$)$, with no indication of any wetting-induced collapse compression. This was followed by shrinkage during the drying stage $\left(\mathrm{B}_{2}-\mathrm{B}_{3}\right)$, with a net reduction of $v$ over the wetting-drying cycle $\left(B_{1}-B_{2}-B_{3}\right)$. During the isotropic loading stage $\left(B_{3}-B_{4}\right)$ the compression curve gradually converged with the curve from Test $\mathrm{A}$, and during subsequent unloading $\left(\mathrm{B}_{4}-\right.$ $\mathrm{B}_{5}$ ) the variation of $v$ was very similar to Test A.

For Test C, Fig. 2 shows that the variation of $v$ during initial loading $\left(\mathrm{C}_{1}-\mathrm{C}_{2}\right)$ was, as expected, almost identical to that from Test $A$. The wetting stage $\left(\mathrm{C}_{2}-\mathrm{C}_{3}\right)$ produced significant reduction of $v$ (collapse compression), and this was followed by shrinkage in the drying stage $\left(\mathrm{C}_{3}-\mathrm{C}_{4}\right)$. The final isotropic loading $\left(\mathrm{C}_{4}-\mathrm{C}_{5}\right)$ and unloading $\left(\mathrm{C}_{5}-\right.$ $\mathrm{C}_{6}$ ) stages produced irreversible compression, with the suggestion of yielding during loading. By the end of the loading stage $\left(\mathrm{C}_{4}-\mathrm{C}_{5}\right)$ the compression curve had not fully converged with the curves from Tests $\mathrm{A}$ and $\mathrm{B}$, and the final value of $v$ after unloading to $\mathrm{C}_{6}$ was still significantly lower than in Tests A and B.

\subsection{Variation of degree of saturation $S_{r}$}

Fig. 3 shows the variations of degree of saturation $S_{r}$ for all three tests. The initial values of $S_{r}$ shown in Fig. 3 for the three samples (at $A_{1}, B_{1}$ and $C_{1}$ ) were all very similar.

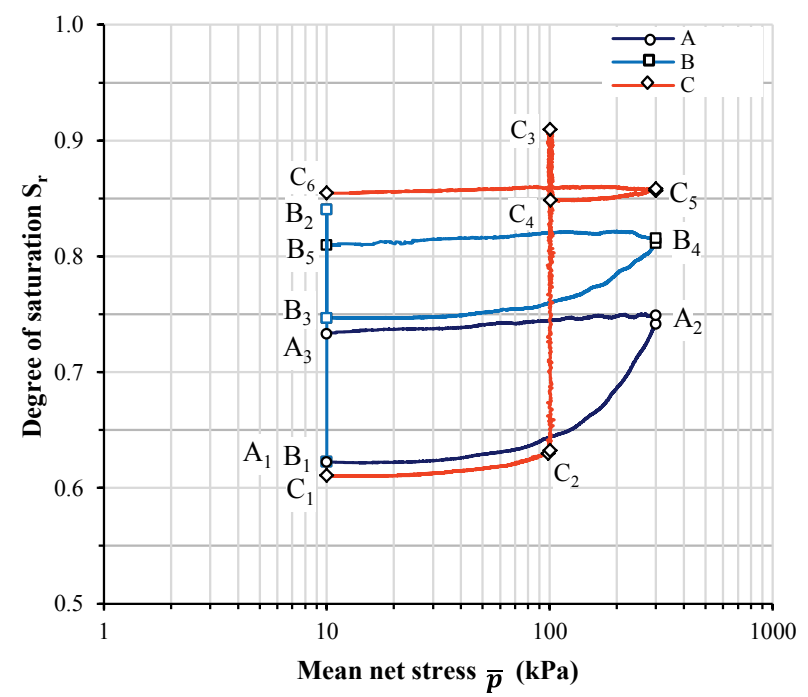

Figure 3. Variation of degree of saturation [15].

The variation of $S_{r}$ during Test A (see Fig. 3) showed significant irreversible increase of $S_{r}$ during the loadingunloading cycle $\left(\mathrm{A}_{1}-\mathrm{A}_{2}-\mathrm{A}_{3}\right)$, with the suggestion of yielding during the loading stage.

In Test B there was significant net increase of $S_{r}$ during the wetting-drying cycle $\left(\mathrm{B}_{1}-\mathrm{B}_{2}-\mathrm{B}_{3}\right)$, as a consequence of hysteresis in the water retention behaviour, so that the value of $S_{r}$ at the start of the subsequent loading stage was higher than in Test $A$ (compare $\mathrm{B}_{3}$ and $\mathrm{A}_{1}$ in Fig. 3). By the end of the loading stages $\left(B_{4}\right.$ and $A_{2}$ in Fig. 3$)$ the difference between the values of $S_{r}$ in Tests $\mathrm{B}$ and $\mathrm{A}$ had reduced, and this difference in $S_{r}$ then remained almost unchanged during the final unloading stages $\left(\mathrm{A}_{2}-\mathrm{A}_{3}\right.$ and $\left.\mathrm{B}_{4}-\mathrm{B}_{5}\right)$.

In Test $\mathrm{C}$ the variation of $S_{r}$ (see Fig. 3) during the first loading stage $\left(\mathrm{C}_{1}-\mathrm{C}_{2}\right)$ was very similar to that in Test $\mathrm{A}$, as expected. A large increase of $S_{r}$ occurred during the wetting stage $\left(\mathrm{C}_{2}-\mathrm{C}_{3}\right)$, with a smaller reduction of $S_{r}$ during the drying stage $\left(\mathrm{C}_{3}-\mathrm{C}_{4}\right)$, as a consequence of hysteresis in the water retention behaviour. Little further change of $S_{r}$ occurred during the final loading stage $\left(\mathrm{C}_{4}-\right.$ $\left.\mathrm{C}_{5}\right)$ and unloading stage $\left(\mathrm{C}_{5}-\mathrm{C}_{6}\right)$, and the value of $S_{r}$ remained higher than in Tests $\mathrm{A}$ and $\mathrm{B}$.

\subsection{Variation of elastic shear modulus $\mathbf{G}$}

The variations of small strain elastic shear moduli $G_{h v}$ and $G_{h h}$ for all three samples A, B and C are plotted in Fig. 4. These values of $G$ were determined from the corresponding values of $V_{s}$, using Eq.(1), where the value of sample bulk density $\rho$ varied throughout each test, as a consequence of changes of $v$ and $S_{r}$. Inspection of Fig. 4 shows that the values of $G_{h v}$ and $G_{h h}$ were always very similar, confirming that the isotropic compaction procedure and subsequent isotropic stress history resulted in soil samples with isotropic properties. 

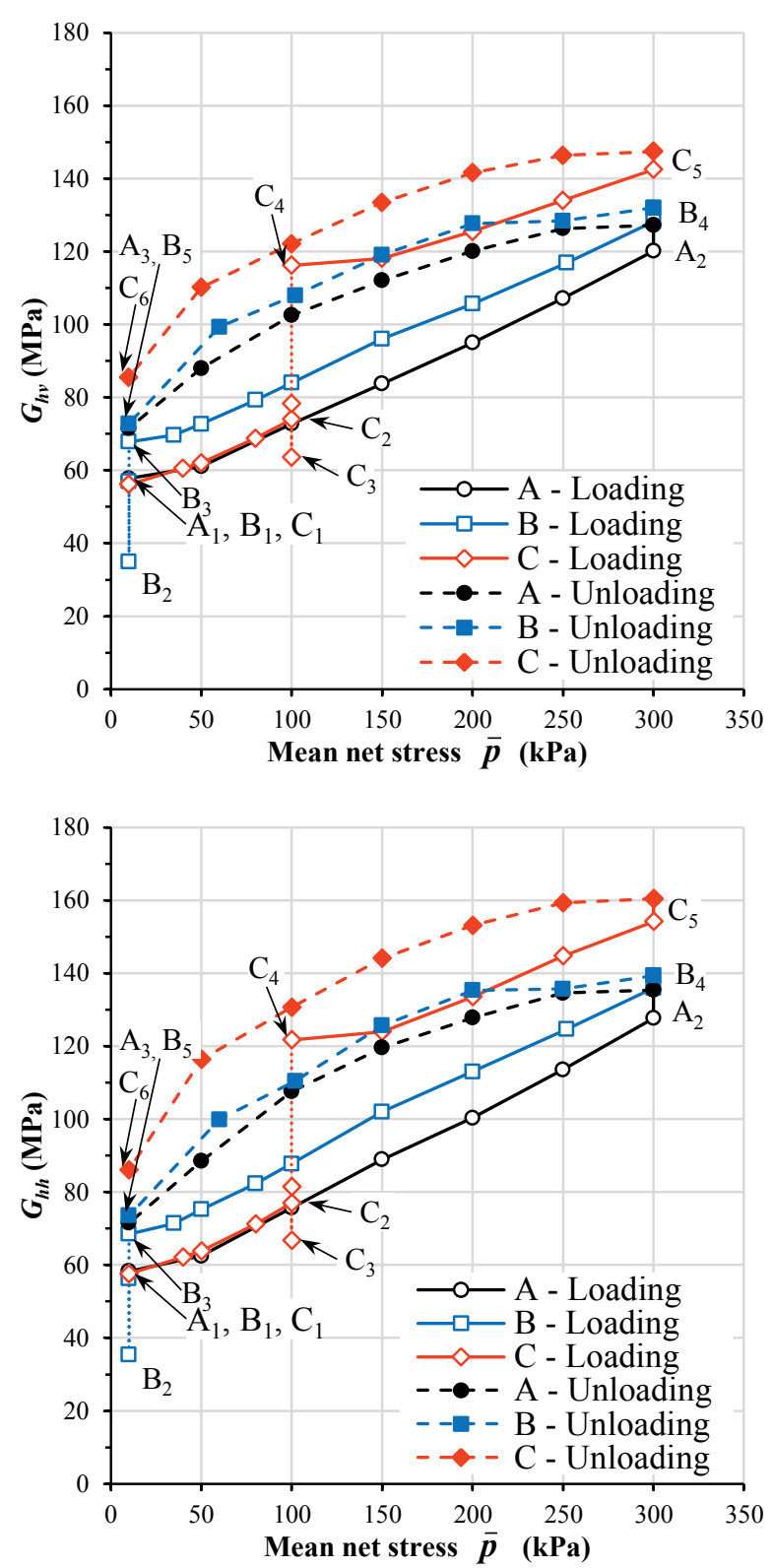

Figure 4. Variation of elastic shear moduli $G_{h v}$ and $G_{h h}$.

Results from Test A in Fig. 4 show that the elastic shear modulus $G$ increased during the loading stage $\left(\mathrm{A}_{1}\right.$ $\left.A_{2}\right)$. During the subsequent unloading stage $\left(A_{2}-A_{3}\right)$, values of $G$ were higher than at the same values of $\bar{p}$ in the loading stage, showing the combined influence of reduced values of $v$ (Fig. 2) and increased values of $S_{r}$ (Fig. 3) during unloading.

For Test B, inspection of Fig. 4 shows that a significant decrease of $G$ occurred during the wetting stage $\left(\mathrm{B}_{1}-\mathrm{B}_{2}\right)$, with a larger increase of $G$ during the subsequent drying stage $\left(B_{2}-B_{3}\right)$. There was therefore a net increase of $G$ over the wetting-drying cycle, attributable to the combined influence of a net decrease of $v$ (Fig. 2) and net increase of $S_{r}$ (Fig. 3).

The values of $G$ during the subsequent loading stage $\left(\mathrm{B}_{3}-\mathrm{B}_{4}\right)$ of Test $\mathrm{B}$ were higher than during the loading stage of Test A, attributable to the combined influence of lower values of $v$ and higher values of $S_{r}$ in Test B (see Figs. 2 and 3). Interestingly, the difference in $G$ values between Tests B and A remained approximately constant throughout the loading stages (see Fig. 4), even though the values of $v$ converged (see Fig. 2) and the difference in values of $S_{r}$ reduced (Fig. 3). During the 24 hour rest period at the end of the loading stages, the difference in values of $G$ between Tests B and A reduced, and the values of $G$ in the two tests then remained very similar during the final unloading stages, despite the higher values of $S_{r}$ in Test B (see Fig. 3).

Values of $G$ during the unloading stage $\left(\mathrm{B}_{4}-\mathrm{B}_{5}\right)$ of Test $B$ were generally higher than at the same values of $\bar{p}$ during the loading stage, as in Test A. However, by the end of the loading-unloading cycle in Test $\mathrm{B}\left(\mathrm{B}_{3^{-}} \mathrm{B}_{4^{-}}\right.$ $\mathrm{B}_{5}$ ) there had been little net change of $G$ over the cycle (compare $\mathrm{B}_{5}$ and $\mathrm{B}_{3}$ in Fig. 4), despite the net changes of $v$ and $S_{r}$ over the cycle.

For Test C, Fig. 4 shows that the variation of $G$ during the initial loading stage $\left(\mathrm{C}_{1}-\mathrm{C}_{2}\right)$ was, as expected, very similar to that observed in Test A (up to this point the two samples had followed the same stress path, see Fig.1). During the wetting stage $\left(\mathrm{C}_{2}-\mathrm{C}_{3}\right)$ of Test $\mathrm{C}$ there was a decrease of $G$, followed by a significantly larger increase of $G$ during the subsequent drying stage $\left(\mathrm{C}_{3}-\mathrm{C}_{4}\right)$. The net increase of $G$ over the wetting-drying cycle of Test $\mathrm{C}$ $\left(\mathrm{C}_{2}-\mathrm{C}_{3}-\mathrm{C}_{4}\right)$ was much greater than during the wettingdrying cycle of Test $B\left(B_{1}-B_{2}-B_{3}\right)$, because the net decrease of $v$ over the cycle was much greater in Test $\mathrm{C}$, due to the occurrence of collapse compression during wetting (see Fig. 2).

During the second loading stage $\left(\mathrm{C}_{4}-\mathrm{C}_{5}\right)$ of Test $\mathrm{C}$ the values of $G$ were higher than in Tests $\mathrm{A}$ and $\mathrm{B}$, due to the combined influence of lower values of $v$ (Fig. 2) and higher values of $S_{r}$ (Fig. 3) in Test C. During the unloading stage $\left(\mathrm{C}_{5}-\mathrm{C}_{6}\right)$ of Test $\mathrm{C}$ the values of $G$ were higher than at the same values of $\bar{p}$ in the loading stage (consistent with observations from Tests A and B).

\section{Interpretation}

The aim in this paper was to investigate whether the experimentally observed variations of small strain shear modulus $G$ could be interpreted solely in terms of mean Bishop's stress $p^{*}$ (defined in Eq.(4)) and specific volume $v$. Fig. 5 shows the calculated variation of mean Bishop's stress $p^{*}$ for one of the tests (Test C), as an example. The value of $p^{*}$ increases during wetting stages (e.g. $\mathrm{Y}-\mathrm{C}_{1}$ and $\mathrm{C}_{2}-\mathrm{C}_{3}$ ) and decreases during drying stages (e.g. $\mathrm{C}_{3}-\mathrm{C}_{4}$ ). Over a wetting-drying cycle (e.g. $\mathrm{C}_{2}-\mathrm{C}_{3}-\mathrm{C}_{4}$ ) there is a net increase of $p^{*}$, due to the increase of $S_{r}$ arising from hysteresis in the water retention behaviour.

\subsection{Proposed expression for $G$}

Based on experience from saturated soils (see Eqs. (2) and (3)), a possible expression relating the variation of $G$ to $p^{*}$ and $v$ for isotropic soils under unsaturated conditions and isotropic stress states is:

$$
G=C v^{-m}\left(p^{*} / p_{a}\right)^{0.5}
$$

where $C$ and $m$ are soil parameters. 


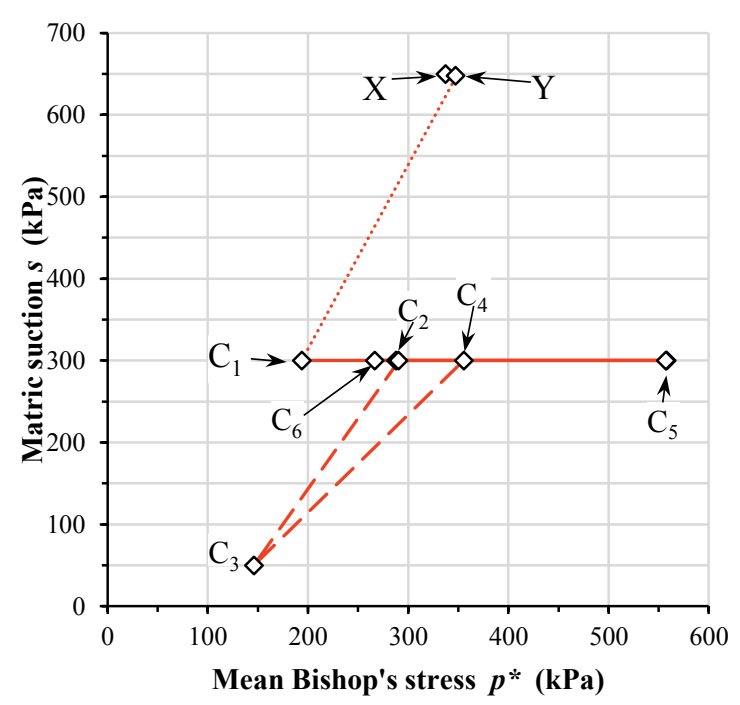

Figure 5. Stress path for Test C in s: $p^{*}$ plane.

Fig. 6 examines the validity of Eq.(6) against the experimental data from Tests $\mathrm{A}, \mathrm{B}$ and $\mathrm{C}$, by plotting $G /\left(p^{*} / p_{a}\right)^{0.5}$ against $v$ on a log-log plot. Each experimental value of $G$ in Fig. 6 was taken as the average of $G_{h v}$ and $G_{h h}$ from Fig. 4. Inspection of Fig. 6 shows that the test data from all three tests fit well to a single straight line in this plot. The 3 data points plotting furthest below the best-fit straight line in Fig. 6 correspond to the three final points at the end of unloading $\left(\mathrm{A}_{3}, \mathrm{~B}_{5}\right.$ and $\mathrm{C}_{6}$ in Fig. 4) and the single data point plotting significantly above the best-fit line in Fig. 6 corresponds to the end of the wetting stage in Test $\mathrm{B}\left(\mathrm{B}_{2}\right.$ in Fig. 4). The gradient and intercept of the best-fit straight line in Fig. 6 correspond to $m=3.60$ and $C=721$ $\mathrm{MPa}$ respectively in Eq.(6).

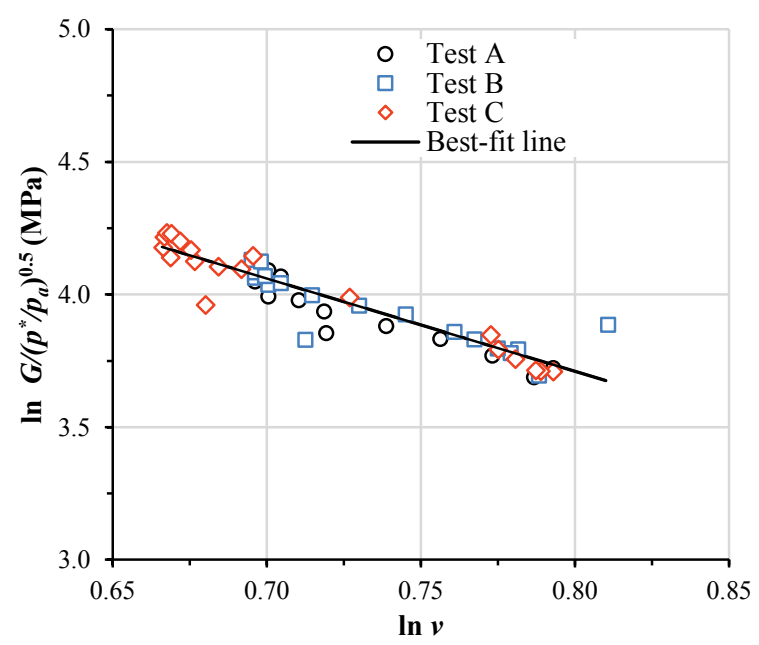

Figure 6. Variation of $\ln G /\left(p^{*} / p_{a}\right)^{0.5}$ against ln $v$.

\subsection{Predicted variations of $G$}

Fig. 7 shows the predicted variations of $G$ from Eq.(6), with $m=3.60$ and $C=721 \mathrm{MPa}$, plotted against $p^{*}$ for Tests A, B and $\mathrm{C}$, together with the corresponding experimental values of $G$.
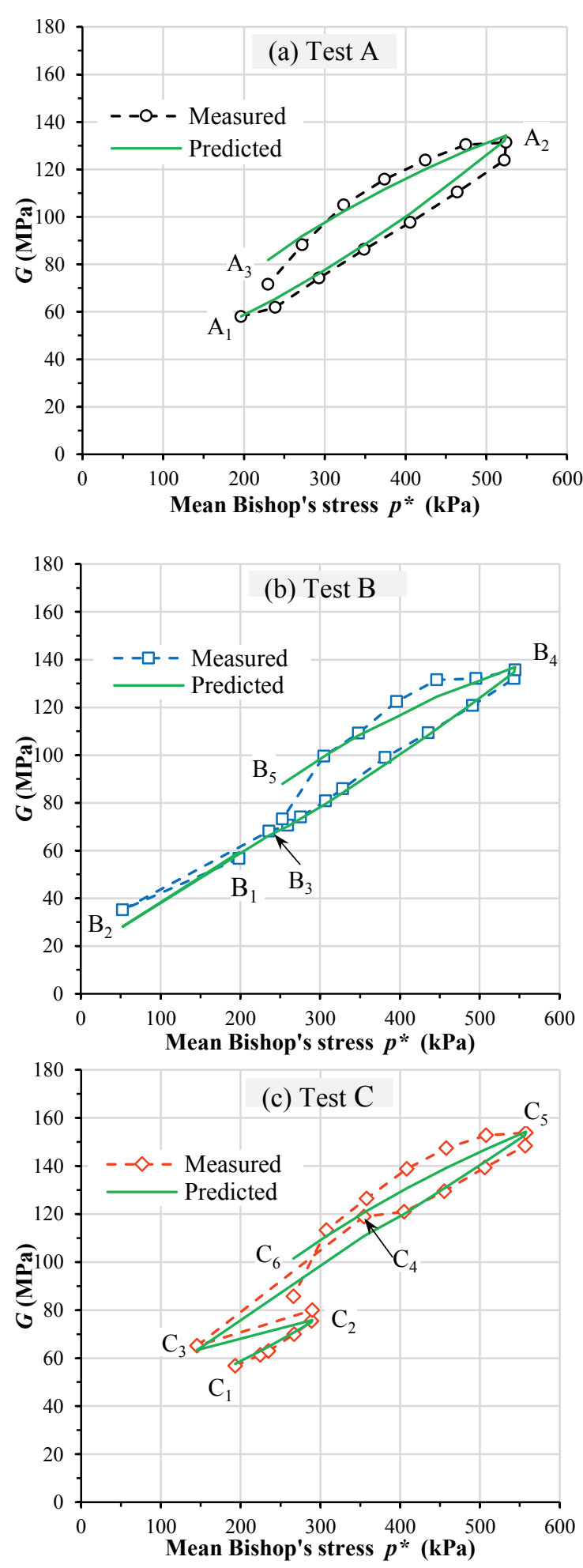

Figure 7. Measured and predicted variations of $G$.

Fig. 7a shows a comparison between measured and predicted values of $G$ for Test A. It is clear from Fig.7a that there was excellent match between measured and predicted values of $G$ during the loading stage $\left(\mathrm{A}_{1}-\mathrm{A}_{2}\right)$. Eq.(6) also correctly predicted that values of $G$ were higher during the unloading stage $\left(\mathrm{A}_{2}-\mathrm{A}_{3}\right)$ than at the same values of $p^{*}$ during the loading stage (because of the lower values of $v$ during unloading). The match between predicted and experimental values of $G$ was, however, less good during unloading than during loading 
and, in particular, the final value of $G$ at the end of unloading was over-predicted by Eq.(6).

For Test B (Fig. 7b), the predicted variation of $G$ during the wetting-drying cycle $\left(\mathrm{B}_{1}-\mathrm{B}_{2}-\mathrm{B}_{3}\right)$ matches well the observed variation, with Eq.(6) predicting a significant reduction of $G$ during wetting $\left(\mathrm{B}_{1}-\mathrm{B}_{2}\right)$, because of the reduction of $p^{*}$ and the increase of $v$ (wetting-induced swelling). Eq.(6) also correctly predicts a net increase of $G$ over the wetting-drying cycle (compare $\mathrm{B}_{3}$ and $\mathrm{B}_{1}$ in Fig. $7 \mathrm{~b}$ ), because of a net increase of $p^{*}$ over the cycle (see Eq.(4) and the values of $S_{r}$ in Fig. 3) and a net decrease of $v$ over the cycle (see Fig. 2). The predicted value of $G$ at the end of wetting $\left(\mathrm{B}_{2}\right)$ did, however, under-predict the corresponding measured value of $G$.

Inspection of Fig. 7b shows that values of $G$ were well-predicted during the loading stage $\left(\mathrm{B}_{3}-\mathrm{B}_{4}\right)$ of Test $\mathrm{B}$, but were less accurately predicted during the subsequent unloading stage $\left(\mathrm{B}_{4}-\mathrm{B}_{5}\right)$. In particular, the final value of $G$ at the end of unloading $\left(\mathrm{B}_{5}\right)$ was again over-predicted by Eq.(6).

For Test $\mathrm{C}$ (Fig. 7c), the predicted variation of $G$ during initial loading $\left(\mathrm{C}_{1}-\mathrm{C}_{2}\right)$, wetting $\left(\mathrm{C}_{2}-\mathrm{C}_{3}\right)$, drying $\left(\mathrm{C}_{3}-\mathrm{C}_{4}\right)$ and subsequent loading $\left(\mathrm{C}_{4}-\mathrm{C}_{5}\right)$ matched well the observed behaviour. Eq.(6) correctly predicted significantly greater net increase of $G$ over the wettingdrying cycle of Test $\mathrm{C}\left(\mathrm{C}_{2}-\mathrm{C}_{3}-\mathrm{C}_{4}\right)$ than over the wettingdrying cycle of Test $B\left(B_{1}-B_{2}-B_{3}\right.$ in Fig. $\left.7 b\right)$, because the net decrease of $v$ over the cycle was much greater in Test $\mathrm{C}$, due to the occurrence of collapse compression during wetting. The variation of $G$ during the final unloading stage of Test $\mathrm{C}$ was not predicted as accurately as during the rest of the test (see Fig. 7c) and the final value of $G$ at the end of unloading $\left(\mathrm{C}_{6}\right)$ was again over-predicted.

Eq.(6), which involves dependency on only $p^{*}$ and $v$, provides reasonable predictions of the variations of $G$ throughout Tests A, B and C. Further investigation showed that incorporating the bonding parameter $\zeta$ as an additional variable, through use of Eq.(5), as proposed by Chao [12], but with a best-fit value for the exponent of $v$, rather than enforcing a value of -3 , led to no significant improvement in fit over Eq.(6). The bonding parameter $\zeta$ depends mainly on $S_{r}$, and further examination of the data from Tests A, B and C indicated that it was unlikely that the mis-matches between predicted and observed variations of $G$ during the final unloading stages in Fig. 7 could be significantly reduced by including dependency on $S_{r}$ as well as $p^{*}$ and $v$ in any proposed expression for G.

\section{Conclusions}

An initial investigation, based on bender element data from three tests on unsaturated compacted kaolin samples, which involved isotropic loading and unloading together with wetting and drying stages, indicated that Eq.(6), which includes dependency on only mean Bishop's stress $p^{*}$ and specific volume $v$, provides a good match to the observed variations of small strain shear modulus $G$. No significant improvement of fit was achieved by incorporating additional dependence on degree of saturation $S_{r}$ or bonding parameter $\zeta$. Eq.(6) reverts to a well-established form for saturated soils at $S_{r}=1\left(\right.$ when $\left.p^{*}=p^{\prime}\right)$. Further validation against a wider range of experimental data is now required.

\section{References}

1. R. Dyvik and C. Madshus, Proceedings ASCE Annual Convention Advances in the art of testing soils under cyclic conditions, Michigan, 186-197 (1985)

2. B. O. Hardin, W. L. Black, Journal of Soil Mechanics \& Foundation Divisions, ASCE, 94, 353369, (1968)

3. G. Viggiani \& J. Atkinson, Géotechnique, 45, 2, 149-154 (1995)

4. S. Oztoprak, M. Bolton, Géotechnique, 63, 1, 54-70, (2013)

5. D. C. Lo Presti, O. Pallara, D. Costanzo, M. Impavido, Pre-failure Deformation of Geomaterials, 1, 11-16 (1995)

6. S. Shibuya, S.C. Hwang, T. Mitachi, Géotechnique, 47, 3, 593-601, (1997)

7. G. T. Houlsby \& C. P. Wroth, Géotechnique, 31, 3, 138-143 (1991)

8. C.Mancuso, R. Vassallo, A. d'Onofrio, Canadian Geotechnical Journal, 39, 1, 22-31 (2002)

9. C. W. W. Ng, S. Yung, Géotechnique, 58, 1, 23-35. (2008)

10. M. Biglari, C. Mancuso, A. d'Onofrio, M. K. Jafari, A. Shafiee, Computers and Geotechnics, 38, 5, 709720 (2011)

11. K. S. Wong, D. Mašín, C. W. W. Ng, Computers and Geotechnics, 56, 28-39 (2014)

12. Z. Chao, PhD thesis, Hong Hong University of Science and Technology (2014)

13. S. J. Wheeler, R. S. Sharma, M. S. R. Buisson, Géotechnique, 53, 1, 41-54 (2003)

14. D. Gallipoli, A. Gens, R. Sharma, J. Vaunat, Géotechnique, 53, 1, 123-135 (2003)

15. A. Hasan, S.J. Wheeler, $6^{\text {th }}$ Asia-Pacific Conf. Unsaturated Soils, Guilin, China, 191-196 (2015)

16. E.C. Leong, S.H. Yeo, H. Rahardjo, Geotechnical Testing Journal, ASTM, 28, 488-498 (2005)

17. A. Hasan, S.J. Wheeler, $16^{\text {th }}$ ECSMGE, Edinburgh, UK, 6, 3171-3176 (2015) 